\title{
Correction to: Epidemic of plague amidst COVID-19 in Madagascar: efforts, challenges, and recommendations
}

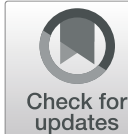

\author{
Abdullahi Tunde Aborode ${ }^{1}$, Ana Carla dos Santos Costa², Anmol Mohan ${ }^{3}$, Samarth Goyal ${ }^{4}$, Aishat Temitope Rabiu ${ }^{5}$, \\ Christos Tsagkaris ${ }^{6}$, Olivier Uwishema ${ }^{7,8,9^{*}}$, Oumaima Outani ${ }^{10}$, Shoaib Ahmad ${ }^{11}$ and Mohammad Yasir Essar ${ }^{12}$
}

\section{Correction to: Trop Med Health 49, 56 (2021) https://doi.org/10.1186/s41182-021-00349-5}

Following publication of the original article [1], the affiliation numbers for the authors Oumaima Outani, Shoaib Ahmad, and Mohammad Yasir Essar were incorrect, and should be changed from Oumaima Outani ${ }^{9,10}$, Shoaib Ahmad $^{10,11}$ and Mohammad Yasir Essar ${ }^{11,12}$ to Oumaima Outani ${ }^{10}$, Shoaib Ahmad ${ }^{11}$ and Mohammad Yasir Essar ${ }^{12}$.

The author affiliation list has been updated above and the original article [1] has been corrected.

\begin{abstract}
Author details
${ }^{1}$ Healthy Africans Platform, Research and Development, Ibadan, Nigeria.

${ }^{2}$ Federal University of Bahia, Salvador, Bahia, Brazil. ${ }^{3}$ Karachi Medical \& Dental College, Karachi, Pakistan. ${ }^{4} \mathrm{KMC}$ Manipal, Manipal, India. ${ }^{5}$ Faculty of Basic Medical Sciences, Kwara State University, Malete, Nigeria. ${ }^{6}$ University of Crete, Faculty of Medicine, Heraklion, Greece. ${ }^{7}$ Oli Health Magazine Organization, Research and Education, Kigali, Rwanda. ${ }^{8}$ Faculty of Medicine, Karadeniz Technical University, 61080 Trabzon, Turkey. ${ }^{9}$ Clinton Global Initiative University, New York, USA. ${ }^{10}$ Faculty of Medicine and Pharmacy of Rabat, Mohamed 5 University, Rabat, Morocco. ${ }^{11}$ District Head Quarters Teaching Hospital, Faisalabad, Pakistan. ${ }^{12}$ Kabul University of Medical Sciences, Kabul, Afghanistan
\end{abstract}

Published online: 29 July 2021

\section{Reference}

1. Aborode, et al. Epidemic of plague amidst COVID-19 in Madagascar: efforts, challenges, and recommendations. Trop Med Health. 2021;49:56. https://doi. org/10.1186/s41182-021-00349-5.

\footnotetext{
The original article can be found online at https://doi.org/10.1186/s41182021-00349-5.

* Correspondence: uwolivier1@ktu.edu.tr

${ }^{7}$ Oli Health Magazine Organization, Research and Education, Kigali, Rwanda

${ }^{8}$ Faculty of Medicine, Karadeniz Technical University, 61080 Trabzon, Turkey

Full list of author information is available at the end of the article
}

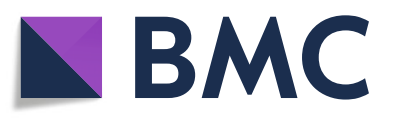

(c) The Author(s). 2021 Open Access This article is licensed under a Creative Commons Attribution 4.0 International License, which permits use, sharing, adaptation, distribution and reproduction in any medium or format, as long as you give appropriate credit to the original author(s) and the source, provide a link to the Creative Commons licence, and indicate if changes were made. The images or other third party material in this article are included in the article's Creative Commons licence, unless indicated otherwise in a credit line to the material. If material is not included in the article's Creative Commons licence and your intended use is not permitted by statutory regulation or exceeds the permitted use, you will need to obtain permission directly from the copyright holder. To view a copy of this licence, visit http://creativecommons.org/licenses/by/4.0/. 